\title{
A ESPIRITUALIDADE E A MORAL NA PRÁTICA DO DOCENTE
}

\section{ARTIGO ORIGINAL}

GERONE, Lucas Guilherme Teztlaff de ${ }^{1}$

BATAGLIA, Patricia Unger Raphael ${ }^{2}$

GERONE, Lucas Guilherme Teztlaff de. BATAGLIA, Patricia Unger Raphael. A espiritualidade e a moral na prática do docente. Revista Científica Multidisciplinar Núcleo do Conhecimento. Ano 05, Ed. 09, Vol. 01, pp. 108-120. Setembro de 2020. ISSN: 2448-0959, Link de acesso: https://www.nucleodoconhecimento.com.br/ciencia-da-religiao/pratica-dodocente

\section{RESUMO}

Contexto: A investigação científica sobre o desenvolvimento moral na educação tem ganhado espaço nas rodas de debates e nas pesquisas acadêmicas, contudo, há poucos estudos que abordam a espiritualidade como uma dimensão do desenvolvimento moral considerando especialmente a área de educação. Objetivos: No presente estudo aborda-se a espiritualidade no desenvolvimento moral, especificamente na prática do docente. $O$ embasamento teórico será fundamentado em Piaget, Kohlberg e Fowler sobre o desenvolvimento moral, religioso e da fé.

${ }^{1}$ Mestre em Teologia pela PUC/PR. Possui Especialização em Comportamento Organizacional; Especialização em Neuropsicopedagogia; Especialização em Filosofia e Sociologia; Especialização em Docência do Ensino Superior. MBAs em Administração e Gestão com ênfase na espiritualidade e religiosidade nas empresas. Graduado em Gestão comercial. Bacharelado em Teologia. Possui Licenciatura em Filosofia e Licenciatura em Pedagogia.

2 Doutorado em Psicologia Social. Mestrado em Psicologia Social. Graduação em Psicologia. 
Resultados: 1) existe uma relação etimológica entre a espiritualidade, o desenvolvimento moral e o docente; 2) existe uma relação histórica entre a espiritualidade-religião, a moral e a educação. Percebe-se uma relação entre a espiritualidade, a moral e prática do docente na busca de uma educação integral e humana, as questões morais e espirituais são indispensáveis; na compreensão dos valores e direitos humanos; como um recurso (coping) para o docente encontrar sentido e propósito profissional e pessoal; no ensino religioso encontram-se valores humanos com efeitos morais como, o respeito, a fraternidade, a solidariedade, o bemestar. Considerações: A contribuição da psicologia da educação para reflexão da espiritualidade, a moral e o docente, tais como, nos significados etimológicos, na busca do conhecimento e sentido-proposito da vida; como um recurso coping espiritual no contexto educacional. Faz-se necessário a continuidade de novas pesquisas que analisem a influência da espiritualidade e da religião no desenvolvimento moral na prática do docente, tais como, na competência moral, em métodos de formação contínua, na prática do ensino moral e religioso, e na construção das virtudes morais.

Palavras-chave: Desenvolvimento moral, educação, espiritualidade, docente.

\section{INTRODUÇÃO}

É com a teoria de Kohlberg (1981) sobre o desenvolvimento moral e o religioso, que Fowler (1992) inspirado por Piaget (1973) desenvolveu estudos sobre a fé como uma dimensão que se constrói cronologicamente com as experiências da vida. Para Kohlberg (1981) e Fowler (1992), o desenvolvimento moral e o religioso são distintos, mas, são associados na busca do sentido e dos valores existenciais, que se constroem nos ambientes educativos: familiares, a comunidade de fé e a comunidade escolar. Neste sentido, os ambientes educativos têm como finalidade primária construir as inteirações entre as dimensões da fé, um aspecto de sentido existencial, com as dimensões educativas: a cultura e os valores morais adquiridos na socialização. 
Entende-se que ensinar é uma arte da vida, o educador é aquele que constrói um diálogo entre as questões morais da sociedade com os valores do aprendiz: seu sentido e propósito, suas necessidades psicoemocionais e espirituais. Neste contexto, este trabalho procura entender a relação entre as questões morais com as espirituais e a influência desta relação na educação, especificamente na prática do docente.

Este estudo estrutura-se da seguinte forma: 1) um panorama das noções etimológicas do estudo. Conhecer as terminologias é um ponto de partida fundamental. Será acunhada a noção de espiritualidade, desenvolvimento moral e docente. 2) Um panorama histórico teórico e prático da relação entre a espiritualidade-religiosidade, a moral e a educação. Conhecer a realidade sócio-histórica permite uma análise sistemática sobre a temática do estudo e de sustentação para discussão do tema. 3) No desenvolvimento moral, religioso e educação utilizam-se as teorias de Kohlberg e Fowler. Com estes autores garante-se a sustentação acadêmica com argumentos válidos para discutir a temática aqui abordada. 4) Por fim, nas considerações são apontadas, as constatações, e as lacunas deste estudo.

\section{O QUE É ESPIRITUALIDADE/RELIGIOSIDADE}

Em primeira, a espiritualidade é uma noção que remete ao estado da natureza do espírito, algo integrado ao homem. Ou seja, uma qualidade e exercício de espírito. De acordo Waldir Souza (2013, p. 97), é "uma condição humana da qual não se escapa". Acrescenta-se: a espiritualidade é uma dimensão existencial dinâmica e de experiências, cultivada no espírito, que impulsiona o ser humano consciente em suas escolhas vitais, formando seu (auto) conhecimento sobre si e do mundo: seus valores morais, a amizade, a conexão, a solidariedade, o humanismo, e o sentido e propósito da vida, a transcendência, que pode (ou não) estar relacionada à religião, aqui entendida a partir de sua etimologia latina, religare, que significa "religação", conexão entre o homem e Deus (DERRIDA, 2000).

No meio acadêmico e popular há uma comparação entre a religiosidade e a espiritualidade. Para Koenig (2012) a maioria das pesquisas sobre religiosidade utiliza a noção de espiritualidade no título ou na discussão dos resultados. Sendo assim, 
nesses estudos a religiosidade e a espiritualidade aparecem juntas. Entretanto, mesmo havendo essa associação, não se pode considerar a religiosidade e a espiritualidade como parecidas. Para Koenig (2012) a religiosidade procede da religião: um sistema de crenças e práticas observado por um grupo de pessoas que se apoiam em rituais ou em um conjunto de escrituras e ensinamentos que reconhecem, idolatram, comunicam-se com ou se aproximam do Sagrado, do Divino, de Deus.

\section{O QUE DESENVOLVIMENTO MORAL}

Entende-se como desenvolvimento uma ação de crescer ou progredir, um crescimento dos atributos individuais psicológicos, morais e intelectuais. O significado de moral provém do latim mos - moris, que denota costume. Entende-se como moral: as regras de conduta, ao âmbito do espírito humano, preceitos estabelecidos e admitidos por uma sociedade que regulam o comportamento de quem dela faz parte (AULETE, 1980).

O desenvolvimento moral está atrelado ao desenvolvimento humano, encontram-se as questões morais em todas as civilizações. Para Vázquez (1987), a moral é um conjunto de normas e regras elaboradas e aceitas por uma civilização, em que se regula a relação social, o comportamento e as normas de governança. Para Vásquez a moral nasce na concordância dos indivíduos em garantir um comportamento de cada um dentro do coletivo (VÁZQUEZ, 1987).

A moral na perspectiva da espiritualidade está na consciência de espírito e nas virtudes. De acordo com Comte-Sponville (1999), a virtude é uma inclinação do ser humano em fazer bem, um espírito em verdade, que remete aos pensamentos e ações morais. Comte-Sponville (1999) acrescenta que a virtude é uma moral aplicada e viva, que transcendente o que é genérico. Para Comte-Sponville (1999) existem virtudes associadas ao espírito e a razão, como por exemplo, a justiça[3].

$\mathrm{Na}$ religião a noção da moral está relacionada à aptidão religiosa, desenvolvida e entendida nos níveis de maturidade religiosa. Ou seja, quanto mais adesão a doutrina 
e ensinamento religioso maior o desenvolvimento moral e social (AMATUZZI, 2000).

É comum encontrar civilizações que se desenvolveram socialmente com influências de doutrinas religiosas, regulamentaram as normas de controle moral, por exemplo, em uma civilização com tradição judaico-cristã é crime matar, roubar ou cometer atos que prejudique a integridade do coletivo, ou seja, não é Legal e moral (Êxodo 20: 117).

Na psicologia existem interpretações sobre a noção de moral e seu desenvolvimento: a) dentro do entendimento behaviorista a noção da moral é formada pelos aspectos externos do que os genéticos e é constituída naquilo que é bom para sociedade é o que permite a sobrevivência, e, o que é bom para o organismo é o que desenvolve o bem-estar, e, o que é bom para a cultura é o que soluciona os problemas (ZILIO; CARRARA, 2009). b) na concepção cognitiva de Bandura a noção de moral é vista no comportamento social, o desenvolvimento ocorre na observação e na imitação. c) Para Freud, a moral é relativa aos ideais que constituem o Eu, que é a representação e conhecimento do homem, enquanto, relaciona-se com o desejo, a culpa e os sentimentos de obrigatoriedade como motivadores da ação moral (GOLDEMBERG, 1994). d) Para os psicólogos construtivistas Piaget e Kohlberg, a pessoa é vista como autor do desenvolvimento moral, em julgar o errado ou certo.

\section{O QUE É DOCENTE}

A etimologia deriva do latim docere que significa 'ensinar' noção está relacionada a quem educa, ensina e ministra aulas, ou, quem constrói valores, normas ou regras. A noção sobre docente possui variações conforme o contexto histórico social, por exemplo, um docente pode ser aquele que ensina as normas e os preceitos religiosos (ROLDÃO, 2007). Para Paulo Freire (2005) a prática docente necessariamente precisa contemplar as experiências do ser humano, seus valores e morais, valorizar a amizade e a conexão, a solidariedade, e promover sentido e propósito da vida.

Para Libâneo (2008, p. 47) "o trabalho docente é uma "atividade fundamentalmente social, porque contribui para a formação cultural e científica do povo". Fischer (2009, p. 94), descreve que a docência é um espaço de "experimentação, de transformação 
de si, de exercício genealógico". O espaço é onde ocorrem os questionamentos "de que modo nós fazemos, desta e não daquela forma; de que modo temos aceitado isto e não aquilo; de que modos têm recusado ser isto ou aquilo, como docentes". Ou seja, um desenvolvimento moral e ético de si mesmo, que está em transformação, aceitação da diversidade e das informações circulantes na sociedade.

\section{HISTÓRICO DA RELAÇÃO ENTRE A RELIGIÃO, A EDUCAÇÃO E A MORAL}

Em todo desenvolvimento da humanidade a religião e a educação estiveram interligadas, por exemplo, nas antigas civilizações europeias é comum encontrar um líder religioso (xamã ou pajé) que ocupava um papel de educador, orientava as normas morais que regulamentavam o comportamento coletivo e pessoal dos indivíduos (BOTSARIS, 2011).

A idade média é o período com a maior relação entre a religião, a educação e a moral. Destaca a autoridade teocrática da Igreja Católica Romana que detinha poder político, educacional e social e impunha os dogmas religiosos nas ordens morais da sociedade, como por exemplo, o que é certo agrada a Deus, o que é errado é contra os padrões de Deus. No intento de manter a ordem moral e religiosa na sociedade, padres ou membros da igreja eram os políticos, educadores ou governantes. Somente no final da idade média diminui o poder da igreja em questões políticas e sociais na sociedade, diminuindo também a imposição religiosa nas questões morais.

No início da modernidade a sociedade democrática substitui a teocracia, de acordo com Kant (1793) é a separação entre a Igreja e sociedade que a pessoa constrói a consciência moral sem a imposição religiosa. Todavia, a religião não deixou de influenciar as questões morais da pessoa, na sua consciência opta em seguir e manter as crenças religiosas, elas podem explicar as questões (i)morais, como por exemplo, a injustiça, o sentido do sofrimento, as limitações da vida, e as imperfeições humanas. É neste contexto que a religião participa da construção moral da pessoa, em suas crenças religiosas é possível encontrar a consciência plena, a justiça, o deleite, a infinidade da perfeição em Deus. Dentro disto, no entendimento de Kohlberg (1981) 
na consciência humana existe uma ordem cósmica[4] sem imperfeição, injustiça e erro que pode ser remetida a crença religiosa.

Para Kohlberg (1981) a moral é um domínio independente da dimensão religiosa, o sujeito pode (ou não) julgar suas ações morais através da crença religiosa, todavia, na vida existem questões que sobrepõem o alcance moral e são explicadas por dimensões religiosas, tais como, "por que fazer o bem?". Ou seja, não é apenas cumprir as regras e normas para o bem-estar social, mas, uma reflexão sobre um real motivo, sentido e propósito moral. Por isso, Kohlberg estabeleceu nos estágios do desenvolvimento moral o sétimo estágio, que teria as explicações religiosas no desenvolvimento moral.

Atualmente de acordo com Kadooka; Lepre e Evangelista (2015) existe uma crise moral, uma ausência de valores humanos nos meios políticos, sociais e educacionais. Neste cenário, a crença religiosa tem sido uma reguladora moral para lidar com a crise, como por exemplo, dentro do contexto na educação, docentes utilizam o coping[5] religioso/espiritual para lidar com as situações de crises, estresses e sofrimento no ambiente escolar ou pessoal. Os docentes também têm utilizado a dimensão religiosa e a espiritual como um meio de encontrar sentido e propósito na busca: da valorização pessoal, do bem estar, e de uma prática pedagógica mais humaniza e integral (ESPÍRITO SANTO, 2008).

\subsection{HISTÓRICO DA RELAÇÃo ENTRE A RELIGIÃO, A MORAL E A EDUCAÇÃO NO BRASIL}

O Brasil tem herança européia, devido ao processo da colonização herdou a tradição judaico-cristã. No auge da colonização ordens religiosas como os jesuítas praticavam ações direcionadas a educação abrindo instituições de ensino. A relação entre a educação e a religião pode ser divida historicamente: entre 1500 a 1800 o ensino era proselitista com intento de evangelizar os negros e os gentios, juntamente com a mensagem religiosa o ensino direcionava-se para reflexões sobre os valores morais relacionados à comunidade e a política. Entre 1500 a 1800 os religiosos ocuparam um importante papel sócio educacional no Brasil, pois, a educação era elitizada, de 
um lado, os nobres tinham facilidade de acesso às escolas, no outro lado, a classe pobre como os escravos e indígenas não tinham nenhum acesso à educação. Neste período, surgem as entidades filantrópicas de maioria religiosas que promoviam à assistência social e educacional a classe pobre. Destaca-se o padre Manuel da Nóbrega da Companhia de Jesus, que fundou na Bahia em agosto de 1549 a primeira "escola de ler e escrever". A visão de Nóbrega era formar cidadãos com senso de dever moral, social e religioso (MATTOS, 1958).

Entre 1800 a 1964 a direção das entidades de cunho educacional passa ser de responsabilidade do Estado, isso ocorre devido à inauguração da República, nela, o Estado torna-se Laico, a partir disto, caberá à responsabilidade do Estado em promover efetivamente uma educação sem o proselitismo religioso (CURY, 2002). A nova República constituía uma rede pública de serviços educacionais sem proselitismo religioso (JUNQUEIRA, 2007). Todavia, mesmo com a separação Oficial entre o Estado e a Igreja, as questões religiosas continuaram no campo da educação.

Um marco importante aconteceu em 1930 com a criação do Ministério da Educação, que apesar de ser Laico foi inspirado no ensino gratuito promovido pelas entidades religiosas. Em 1931 o Ministro da Educação Francisco Campo introduziu o ensino religioso nas escolas como parte da construção filosófica e moral. Outro marco é quando o Ensino Religioso foi introduzido na primeira LDBEN Lei de Diretrizes de Base da Educação Nacional em 1961 Lei 4.024 (JUNQUEIRA, 2007). Em seguida por outra versão em 1971, a estrutura ideológica da LDB estava atrelada aos pensamentos e posicionamentos das classes sociais, políticas e religiosas. Nota, pelo menos dois grupos, os estatistas e os liberais, entre as pautas, discutiam o papel do Estado, da família, e as questões morais, que na maioria das vezes interligada com valores religiosos. Posteriormente, o ensino religioso[6] é introduzido na LDB de 1996 como uma disciplina facultativa.

Na Base Nacional Comum Curricular (BNCC) elaborada em 2015, regulamentam-se as aprendizagens essenciais a serem trabalhadas no ensino que visem a promoção da igualdade, a formação integral, e uma sociedade democrática e inclusiva. $\mathrm{Na}$ BNCC o Ensino Religioso é composto por temáticas com reflexões que tratam a 
espiritualidade e a moral, tais como, as Identidades e alteridades: "O eu, o outro e o nós". O conhecimento e o pensamento sobre as crenças e divindades relacionadas à filosofia vida: representações e comportamento religioso, modo de viver, sentimentos e memórias e saberes.

Nas décadas de 70 a 80 na área da educação destaca-se Paulo Freire que teve uma visão integral da educação, Freire abordou temas da ética-moral, da espiritualidade como formas de liberdade da opressão do sistema (FREIRE, 2005).

Atualmente de acordo com Dados do IBGE referentes ao Censo de 2010 sobre a religião divulgam que $86,8 \%$ da população brasileira é composta de cristãos católicos e protestantes (AZEVEDO, 2012). Para Moreira-Almeida (2010) a religião é um fator social, pois é seguida pela maior parte da sociedade e influencia a política, a cultural, e a educação.

\section{O DESENVOLVIMENTO MORAL, RELIGIOSO E A EDUCAÇÃO}

É com a visão construtivista de Piaget e a visão cognitivo-estrutural de Kohlberg que a pessoa é a autora da construção moral através do julgamento do certo e errado (LOURENÇO, 1992). No contexto da moral e a religião, Kohlberg (1981) distingui o pensamento religioso e moral, todavia, associa-os nos estágios de desenvolvimento. Para Kohlberg (1981) dentro do desenvolvimento moral existem questões que são respondidas pelas dimensões religiosas. Como por exemplo, o porquê ser moral? É bom ou mau? A resposta está em cumprir as normas como equilibro social, mas, também envolve uma reflexão individual do sentido e propósito de ser, tal reflexão é cultivada na natureza de espírito e pode respondida pelas dimensões religiosas: Deus é bom e deseja que o homem seja bom: "Toda a boa dádiva e todo o dom perfeito vem do alto, descendo do Pai das luzes, em quem não há mudança nem sombra de variação. Segundo a sua vontade, ele nos gerou pela palavra da verdade, para que fôssemos como primícias das suas criaturas." (Tiago 1:16-18). Entende no trecho bíblico que a bondade vem de Deus, Ele criou o homem para ser bom. Neste exemplo, percebe como as dimensões religiosas podem responder a questão de ser moral. 
As dimensões religiosas como um aspecto moral que proporcione sentido é abordado por James Fowler[7] (1981), que influenciado por Piaget (1973) desenvolveu os estágios da fé que ocorre cronologicamente, "ao nascer, somos dotados de capacidades inatas para a fé", com o decorrer da vida a fé se desenvolve na inteiração com ambientes educativos: pais, familiares, a comunidade de fé (FOWLER, 1992). Dentro disto, os ambientes educativos possuem em sua finalidade construir inteirações entre as dimensões da fé, "um aspecto genérico da luta humana para achar e manter sentido de vida" (FOWLER, 1981), com as dimensões educativas da vida: o conhecimento imediato, a socialização, a cultura, e os valores morais. Neste contexto, para Espírito Santo (2008) o ensinar é uma arte da vida, o educador é aquele que constrói o diálogo entre as questões morais da sociedade com os valores do aprendiz: seus sentidos e propósitos, suas necessidades psicoemocionais, anseios e outros.

\section{CONSIDERAÇÕES}

Nas reflexões etimológicas sobre a espiritualidade, o desenvolvimento moral e o docente encontram-se relações e semelhanças nos significados, como por exemplo, o sentido-propósito é uma dimensão que compõem a noção da espiritualidade, da moral e da prática do docente. Neste contexto, a Psicologia da Educação pode contribuir nas reflexões etimológicas sobre o sentido-propósito como parte da natureza de espírito (pisque), que compreende o comportamento moral, o conhecimento de si e do mundo (SANTOS, 2019).

A história aponta uma relação entre as questões morais e religiosas no contexto educacional, especialmente no Brasil existe uma influência da tradição judaica cristã no contexto educacional. Para o psicólogo educacional La Taille (2009) a valorização da tradição judaico cristã não se trata de incentivar o proselitismo religioso na educação, assim como ocorrido antes do Estado laico. Também, não se trata de um catecismo no ensino, mas, entende-se que a prática de educar não se constrói em perspectiva futurista, ensina-se o que já existe com referência ao passado, portanto, educa-se por meio dos fundamentos culturais e da história. Isso possibilita um conhecimento de si, por sua vez, colabora para um sentido da vida. 
De acordo Kohlberg o desenvolvimento moral e o religioso estão associados na busca de respostas existenciais, como, no sentido e propósito de vida. Para Fowler, os estágios da fé (entendida como a espiritualidade) é um recurso para a busca de sentido e experiências na vida, que se constrói na inteiração com ambientes educativos, família, escola e sociedade.

Conforme erguido neste estudo, atualmente maior parte da população é religiosa (84\% cristão). De acordo La Taille (2009), em uma pesquisa realizada pelo Ministério da Ciência e Tecnologia e pela Academia Brasileira de Ciências revelou que $49 \%$ das pessoas têm como maior interesse no conhecimento o tema da religião. Sobre isso, considera-se a influência da religião na construção do conhecimento que se expressa no contexto educacional, isso não significa que se deve ter uma prática educacional religiosa confessional ou proselitista, mas um ensino laico em seu sentido pleno, respeitar, assegurar, e garantir a liberdade de todas as crenças religiosas. Neste contexto, o ensino religioso enquanto uma disciplina não deve ser um meio de catecismo, mas, um estudo do fenômeno religioso, a liberdade e diversidade de crença, a história e a cultural religiosa, a formação cidadã em valores morais universais, a paz, solidariedade, amor, tolerância, cooperação, honestidade, respeito e justiça (BOEING, 2009). Neste sentido, a prática do educador visa o desenvolvimento humano, no amor, na cooperação, na liberdade, na igualdade com singularidade, na integração dos eixos corporal, relacional, sócio-cultural e de fé.

A espiritualidade é um recurso (coping) para o docente encontrar sentido e propósito profissional e pessoal. De acordo Takiuti (1997) o contexto educacional pode ser estressante, o que interfere negativamente nos estados emocionais, cognitivos e comportamentais e resulta insegurança, incapacidade, inferioridade e outros sentimento negativos. Para Takiuti (1997) o coping espiritual no contexto educacional proporciona a resiliência, a coragem, a autoestima o que influência positivamente a aprendizagem.

Por fim, considera-se importante o desenvolvimento de novas pesquisas sobre: a influência da crença religiosa na competência moral dos docentes; métodos de formação contínua dos docentes que contemplam as questões morais e espirituais; 
estudos sobre os conflitos entre as questões morais e religiosas no contexto educacional, por exemplo, as ideologias de gênero e as crenças religiosas.

\section{REFERÊNCIAS}

AMATUZZI, Mauro Martins. O desenvolvimento religioso: uma hipótese psicológica. Estud. psicol. (Campinas), Campinas, v. 17, n. 1, p. 15-30, Apr. 2000 - Avai-lable from <http://www.scielo.br/scielo.php?script=sci_arttext\&pid=S0103$166 \times 2000000100002 \& \operatorname{lng}=e n \& n r m=i s o>$. access on 19 Nov. 2019. http://dx.doi.org/10.1590/S0103-166X2000000100002.

AULETE, Caldas. Dicionário contemporâneo da Língua Portuguesa. 3. ed. Rio de Janeiro: Delta, 1980. v. 5.

AZEVEDO, R. "O IBGE e a religião - Cristãos são $\mathbf{8 6 , 8 \%}$ do Brasil; católicos caem para 64,6\%; evangélicos já são 22,2\%". Disponível em: $<$ http://veja.abril.com.br/blog/reinaldo/geral/o-ibge-e-a-religiao-\%E2\%80\%93cristaos-sao-868-do-brasil-catolicos-caem-para-646-evangelicos-ja-sao-222/>. Acesso em 29 de julho de 2014.

BíBLIA DE JERUSALÉM. São Paulo: Paulus, 2002.

BOFF, L. Evangelho do Cristo cósmico, Record, 2010.

BOTSARIS. A. S. Sem anestesia: o desabafo de um médico. Os bastidores de uma medicina cada vez mais distante e cruel. Rio de Janeiro: Objetiva, 2001.

BOEING, Antônio. Ensino Religioso enraizado nas Ciências da Religião. Dialogo Revista do Ensino Religioso. №55, agosto/setembro, 2009.

BRASIL. Base Nacional Comum Curricular: Educação é a base. Disponível em: http://basenacionalcomum.mec.gov.br/images/BNCC_El_EF_110518_versaofinal_ site.pdf. Acesso em: 22 de Agosto de 2020. 
BRASIL. Lei de Diretrizes e Bases da Educação Nacional. Lei número 9394, 20 de dezembro de 1996.

CURY, Carlos Roberto Jamil. Direito à educação: direito à igualdade, direito à diferença. Cad. Pesqui. São Paulo, n. 116, p. 245-262, julho de 2002.

COMTE-SPONVILLE, André. Pequeno tratado das grandes virtudes. São Paulo: Martins Fontes, 1999. 225 p.

DERRIDA, Jacques; VATTIMO, Gianni (orgs.). A religião: o seminário de Capri. São Paulo: Estação Liberdade, 2000.

ESPIRITO SANTO, Rui Cezar do. 0 renascimento do sagrado na Educação.Petrópolis: Vozes, 2008.

FISCHER, R. M. B. Docência, cinema e televisão: questões sobre formação ética e estética. Revista Brasileira de Educação. Jan./abr. 2009. oㅜ 40. p. 93 - 102.

FOWLER, J. W. (1981). Stages of Faith. The Psychology of Human Devel-opment and the Quest for Meaning. San Francisco: Harper\&Row.

FOWLER, James W. Estágios da Fé: a psicologia do desenvolvimento humano e a busca de sentido. São Leopoldo: Sinodal, 1992.

FREIRE, P. Pedagogia do Oprimido. 49 ed. Rio de Janeiro: Paz e Terra, 2005.

GOLDEMBERG, R. Ensaio sobre a moral de Freud. Salvador: Ágalma, 1994.

JUNQUEIRA, Sérgio Rogério Azevedo. Formação Docente. Diálogo - Revista do Ensino Religioso $n^{\circ} 45$ - Fevereiro/2007.

KADOOKA, A; LEPRE, R; EVANGELISTA, V. Encontro Nacional de Ensino, Pesquisa e Extensão, Presidente Prudente, 19 a 22 de outubro, 2015. Considerações Sobre A Educação Moral De Kohlberg. Disponível em: http://www.unoeste.br/site/enepe/2015/suplementos/area/Humanarum/Psicologia/CO 
NSIDE-

RA\%C3\%87\%C3\%95ES\%20SOBRE\%20A\%20EDUCA\%C3\%87\%C3\%830\%20MO RAL\%20DE\%20KOHLBERG.pdf. Acesso em 22 de Nov de 2019.

KANT, I. (1974). Crítica da Razão Prática. Rio de Janeiro: Ediouro. (trabalho original publicado em 1788).

KOENIG, H. Medicina, religião e saúde: o encontro da ciência e da espiritualidade. Porto Alegre: LMP, 2012.

KOHLBERG, L. (1981). Ensaios sobre o Desenvolvimento Moral. Volume I; A filosofia do desenvolvimento moral. Nova lorque.

LIBÂNEO, José C. Didática. (Coleção Magistério. Série formação do professor); São Paulo: Cortez, 2008

LOURENÇO, O. M. (1992). Psicologia do desenvolvimento moral: teoria, dados e implicações. Coimbra: Almedina.

MATTOS, Luiz Alves de. Primórdios da educação no Brasil: o período heróico (1549- 1570). Rio de Janeiro: Aurora, 1958.

MOREIRA-ALMEIDA A, et al. "Envolvimento religioso e fatores sociodemográficos: resultados de um levantamento nacional no Brasil". Revista de Psiquiatria Clínica v. 37, n. 1, 2010. Disponível em: <http://www.scielo.br/scielo.php?pid=S010160832010000100003\&script=sci_arttext>. Acesso em 29 de setembro de 2013.

PANZINI, R. Escala de coping religioso-espiritual (escala cre). Dissertação de Mestrado em Psicologia. Porto Alegre: Universidade Federal do Rio Grande do Sul, 2004.

PIAGET, J. O nascimento da inteligência na Criança. Rio de Janeiro: Zahar Editores, $1973,3^{\circ}$ edição. 
ROLDÃO, M. C. Função docente: natureza e construção do conhecimento profissional. Revista Brasileira de Educação, Campinas, v.12, n. 34, p. 94-103, jan./abr. 2007.

SANTOS, David Moises Barreto dos. Educação para sentido na vida e valores: percepção de universitários a partir do livro "Em busca de sentido", de Viktor Frankl. Rev. Bras. Estud. Pedagog., Brasília, v. 100, n. 254, p. 230-252, Apr. 2019

Available from <http://www.scielo.br/scielo.php?script=sci_arttext\&pid=S2176$66812019000100230 \&$ Ing=en\&nrm=iso $>$. access on 04 May 2020. Epub May 16, 2019. https://doi.org/10.24109/2176-6681.rbep.100i254.3911.

SOUZA, W. "A espiritualidade como fonte sistêmica na Bioética". Rev. Pistis Prax., Teol. Pastor., Curitiba, v. 5, n. 1, pp. 91-121, jan./jun. 2013.

TAKIUTI, A. D. A saúde da mulher adolescente - 1993. In: MADEIRA F. R. (Org.). Quem mandou nascer mulher? Estudos sobre crianças e adolescentes pobres no Brasil. Rio de Janeiro: Record, 1997. p. 213-290 Vasquez, S. (1987). Ética. Rio de Janeiro: Editora Civilização Brasileira S.A.

ZILIO, D.; CARRARA, K. (2009). B. F. Skinner: teórico da ciência e teórico da moral? Arquivos Brasileiros de Psicologia, 61(2), 1-12.

\section{APÊNDICE - REFERÊNCIAS DE NOTA DE RODAPÉ}

3. Para Comte-Sponville (1999), assim como Piaget (1994) acredita a noção de justiça é a mais racional das noções morais, por ser analisada psicologicamente e resultante em cooperação. Entende-se como justiça um ideal de valores ou aquilo que é justo.

4. Pelo entendimento de ordem cósmica: Precisamos sentir que somos carregados pela mesma energia que fez surgir a Terra, as estrelas e as galáxias; essa mesma energia fez emergir todas as formas de vida e a consciência reflexa dos humanos; é ela que inspira os poetas, os pensadores e os artistas de todos os tempos; estamos imersos num oceano de energia que vai além da nossa compreensão. Mas essa 
energia, em última instância, nos pertence, não pela dominação mas pela invocação (BOFF, 2010).

5. O coping surgiu na psicologia, uma palavra derivada do inglês que não possui tradução literal em português, podendo significar "lidar com", "manejar", "enfrentar" ou "adaptar-se a". é recurso comportamental e cognitivo (PANZINI, 2004, p. 20).

6. O conhecimento do Fenômeno Religioso, elaborado pelas Ciências da Religião e sistematizado pelo currículo da Educação Básica faz parte da construção cultural da sociedade. Com o Espírito de ressignificar as diferentes dimensões da vida humana. E o Ensino Religioso como componente da formação cidadã torna-se não espaço de releitura e ressignificação do Fenômeno Religioso como também de respeito à pluralidade de cada contexto sociocultural (BOEING, 2009, p. 10-11)

7. James W. Fowler é teólogo, psicólogo, professor de religião e desenvolvimento Humano. Destaca-se seu livro Estágios da Fé (1981) no qual ele aborda sobre o desenvolvimento da fé, religião. Os seis estágios dos quais se desenvolve a fé: (1) fé indiferenciada, (2) fé intuitiva projetiva, (3) fé mítico literal, (4) fé individuativoreflexiva, (5) fé conjuntiva e (6) fé universalizante.

Para Fowler a fé é um aspecto genérico da luta humana para achar e manter sentido, e que ela pode ou não exprimir-se pela religião"(p.83). de acordo com Fowler faz parte da natureza humana buscar sentido e, este está associado a fé que pode ou não levar para práticas religiosas. Pode entender que Fowler separa fé e religião, sendo fé é "mistério que nos envolve" (p.39), uma "realidade transcendente" (p.168), em outra palavras pode-se entender fé como espiritualidade

Enviado: Agosto, 2020.

Aprovado: Setembro, 2020. 